\title{
El delito previo en el lavado de activos: ¿autonomía sustantiva o autonomía procesal?
}

\section{The Prior Crime in Money Laundering: Substantive Autonomy or Procedural Autonomy?}

Luis Rubén Yanqui Machaca* http://dx.doi.org/10.21503/lex.v15i20.1444

* Egresado de la Universidad Alas Peruanas, filial Juliaca. Maestrando por la Universidad Nacional Mayor de San Marcos. Asistente legal en el Estudio Oré Guardia Abogados. Correo electrónico: raw_ruben@hotmail.com

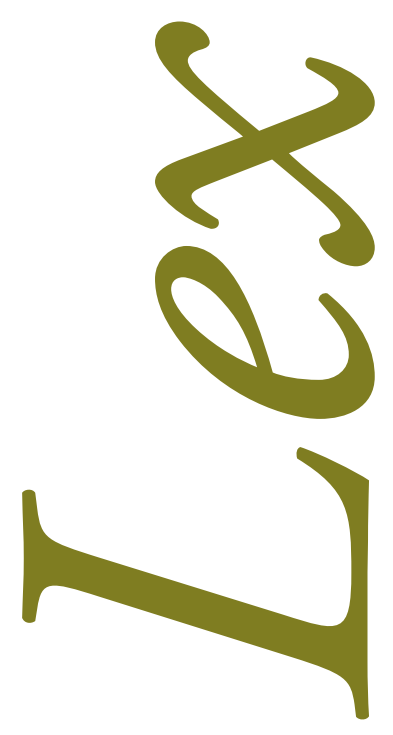

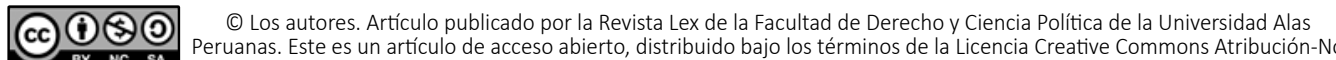
Comercial-Compartir Igual 4.0 Internacional.(http://creativecommons.org/licenses/by-nc-sa/4.0/), que permite el uso no comercial, distribución y reproducción en cualquier medio, siempre que la obra original sea debidamente citada. 


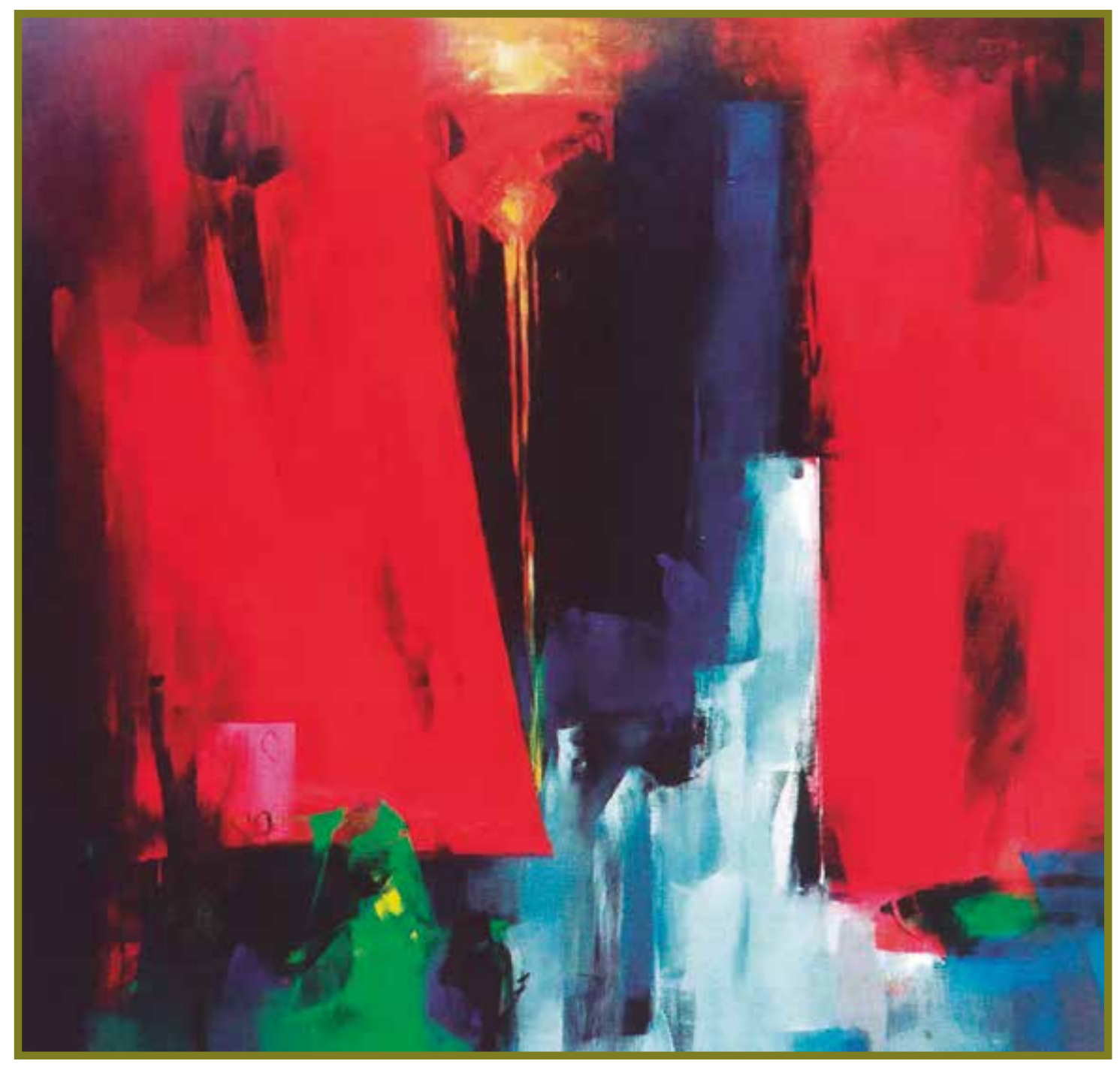

Raúl Cárdenas. Torrentes sin tiempo. 150 x $150 \mathrm{~cm}$. 


\section{RESUMEN}

El autor considera que la interminable discusión académica respecto a la autonomía del delito de lavado de activos se ha centrado en posturas extremas, confundiendo así al operador jurídico. Asimismo, considera que hay formas de compatibilizar ambas posturas (extremas) teniendo en cuenta la eficacia de la administración de justicia y las garantías penales, procesales y constitucionales. En ese sentido, desarrolla su postura intermedia a partir de dos principios constitucionales: el principio de legalidad y el principio de imputación necesaria.

Palabras clave: autonomía sustantiva, autonomía procesal, legalidad, imputación necesaria, origen ilícito, procedencia ilícita, delito previo.

\section{ABSTRACT}

The author considers that the endless academic discussion regarding the autonomy of the money laundering crime has focused on extreme positions, thus confusing the legal operator. He also considers that there are ways of making both positions (extreme positions) compatible, taking into account the effectiveness of the administration of justice and criminal, procedural and constitutional guarantees. In this sense, the author develops an intermediate position on the basis of two constitutional principles: the principle of legality and the principle of necessary imputation.

Key words: substantive autonomy, procedural autonomy, legality, necessary imputation, illegal origin, prior crime. 


\section{PRELIMINARES}

El delito de lavado de activos es un fenómeno criminal que en la actualidad representa uno de los mayores problemas del Estado — en cuanto a su persecución, punición y prevención-. Ante casi tres décadas de lucha en el ámbito nacional, los resultados arrojados están lejos de alcanzar los niveles de eficiencia esperados, pues basta mencionar el escaso registro de condenas para darnos cuenta de ello; y es que desde enero de 2013 hasta febrero de 2014 la Sala Penal Nacional solo emitió 15 sentencias por lavado de activos, de las cuales solo ocho fueron condenatorias. ${ }^{1}$

$\mathrm{Al}$ respecto, cabe preguntarnos: ¿no hay condenas porque en el Perú hay poquísimos lavadores o porque el sistema de administración de justicia está fallando? El profesor Carlos Caro considera que lo que está fallando es el estudio adecuado de la jurisprudencia, la concordancia de la jurisprudencia en torno a lo que se llama el "delito precedente", ${ }^{2}$ y es que el "delito precedente" o "delito previo" se ha convertido en uno de los temas de mayor discusión en el delito de lavado de activos.

Por un lado, se encuentra la postura que considera que el delito de lavado de activos goza de una autonomía sustantiva, razón por la cual consideran que no es necesario acreditar el delito previo; en ese sentido, el 15 de mayo de 2013, el secretario general del Ministerio Público - en ese entonces el Dr. Eduardo Vladimir Cueva Poma - mediante Oficio Circular No 024-2013-MP-FN-SEGFN, dirigiéndose a los presidentes de las juntas de fiscales superiores de los distritos fiscales, señaló lo siguiente:

Tengo el agrado de dirigirme a ustedes, por especial encargo del señor fiscal de la $\mathrm{Na}$ ción, a fin de indicarles que, conforme a lo establecido en el artículo 10 del Decreto

1 Víctor Roberto Prado Saldarriaga, "Jurisprudencia reciente de la Corte Suprema relacionada con el delito de lavado de activos", acceso el 28 de mayo de 2017, http://www.mpfn.gob.pe/escuela/contenido/actividades/docs/3247_lav_activos_2.pdf.

2 Conferencia brindada para el CNM, acceso el 28 de mayo de 2017, https://www.youtube.com/watch?v=BpoGNR6jXdo\&feature=youtu.be. 
Legislativo $\mathrm{N}^{\circ} 1106$-Decreto Legislativo de lucha eficaz contra el lavado de activos y otros delitos relacionados a la minería ilegal y crimen organizado-, el lavado de activos es un delito autónomo, y no tiene delito fuente, por lo que para su investigación y procesamiento no es necesario que las actividades criminales que produjeron el dinero, los bienes, efectos o ganancias, hayan sido descubiertas, se encuentren sometidas a investigación, proceso judicial o hayan sido previamente objeto de prueba o de sentencia condenatoria. En tal sentido, solicito a ustedes, se sirvan instruir a los señores fiscales a cargo de las investigaciones sobre lavado de activos de cada uno de sus distritos fiscales, con la finalidad que se dé estricto cumplimiento a lo dispuesto por dicha norma, bajo responsabilidad de comunicar a las fiscalías desconcentradas de Control Interno la no observancia de la misma.

Por otro lado, se encuentra la postura que considera que el delito previo es un elemento normativo del tipo penal de lavado de activos, razón por la cual tiene que ser materia de acreditación. A favor de esta postura se encuentran los profesores Pariona Arana, ${ }^{3}$ Hinostroza Pariachi, ${ }^{4}$ Castillo Alva, ${ }^{5}$ entre otros.

A nivel jurisdiccional el problema continúa; basta señalar como ejemplo el Acuerdo Plenario No 3-2010/CJ-116 del 16 de noviembre de 2010 que señaló que "el delito fuente, empero, es un elemento objetivo del tipo legal — como tal debe ser abarcado por el dolo- y su prueba condición asimismo de tipicidad"; sin embargo, en ese mismo plenario se señala: "No es una exigencia del tipo penal que el agente conozca de qué delito previo se trata, ni cuándo se cometió este, ni mucho menos quiénes intervinieron en su ejecución. Tampoco el dolo del agente tiene necesariamente que abarcar la situación procesal del delito precedente o de sus autores o partícipes".

Ahora bien, en lo sucesivo desarrollaré ambas posturas, para, en base a ello, tomar una posición al respecto, una posición a partir de una interpretación dogmática, sistemática y constitucional de la norma penal.

\section{TESIS DE LA AUTONOMÍA DEL DELITO DE LAVADO DE ACTIVOS (SUS- TANTIVA Y PROCESAL)}

Los defensores de esta tesis consideran que ninguna de las normas del desarrollo normativo nacional considera al delito previo como un elemento del tipo penal de lavado de activos; consecuentemente, no es necesario acreditarlo en el proceso de lavado de activos o que haya

3 Raúl Pariona Arana, "La ilusión de la autonomía del delito de lavado de activos después de la dación del Decreto Legislativo $\mathrm{N}^{\circ} 1249$, ¿se puede condenar legítimamente a una persona por lavado de activos sin probar que los bienes objeto del delito provienen de la comisión de un delito previo?", Gaceta Penal, n. 90 (2016).

4 César Hinostroza Pariachi, El delito de lavado de activos. Delito fuente (Lima: Grijley, 2010), 142.

5 José Luis Castillo Alva, "La necesidad de determinación del delito previo en el delito de lavado de activos. Una propuesta de interpretación constitucional”, Gaceta Penal, n. ${ }^{\circ}$ (2009): 340. 
sido acreditado en un proceso distinto, bastando con establecer una vinculación razonable de los hechos materia de lavado con dicho delito previo. ${ }^{6}$

El argumento sustancial es que si se considerara al delito de lavado de activos como estructura típica totalmente dependiente del delito previo, simplemente el tipo penal resultaría inaplicable, pues solo generaría la impunidad de los actos concomitantes del sistema económico y generatrices de la ineficacia de la administración de justicia en cuanto a la prevención, investigación y represión del estos delitos, lo que a su vez significa una burla a las expectativas sociales y una defraudación de la finalidad político-criminal que inspiró la configuración del delito de lavado de activos, tanto en los convenios internacionales así como en las propias legislaciones nacionales. ${ }^{7}$

En ese sentido, se señala que esa es la razón por la que diversas legislaciones, especialmente la nuestra, han ido evolucionando a fin de plasmar la autonomía del delito de lavado de activos. Ahora bien, la defensa de esta tesis parte de la redacción del artículo 10 del Decreto Legislativo 1106, modificado por el Decreto Legislativo 1249, el cual estipula:

El lavado de activos es un delito autónomo por lo que para su investigación, procesamiento y sanción no es necesario que las actividades criminales que produjeron el dinero, los bienes, efectos o ganancias, hayan sido descubiertas, se encuentren sometidas a investigación, proceso judicial o hayan sido previamente objeto de prueba o condena

En razón a este artículo, el profesor Gálvez Villegas afirma que "con esta redacción se determina de modo expreso la autonomía material (no solo procesal) de los tipos penales de lavado de activos respecto a la actividad criminal previa; resultando relevante que en el artículo $10^{\circ}$ de esta norma se haga referencia a "actividades criminales" en general y no a un delito previo concreto o específico (supuestos que son totalmente distintos)" ${ }^{8}$ dejando en claro, así, que el delito previo no es un elemento objetivo del tipo, ya que la norma penal no exige delito previo alguno para la configuración del tipo penal, bastando que los activos que constituyen el objeto del lavado de activos tengan una conexión o vinculación con una actividad criminal previa (de modo general o abstracto) y no así de un delito específico, cometido en determinada fecha, por determinada persona, en determinado lugar y en determinadas circunstancias. ${ }^{9}$

Por último, se señala que si solo se sostuviera una autonomía procesal, no tendría ninguna explicación la evolución de la legislación peruana, en la que cada vez se ha incidido en la au-

6 Cfr. Tomás Aladino Gálvez Villegas, Dictamen n. ${ }^{\circ}$ 1132-2012-MP-FN-1FSP, Sala Penal Nacional, Expediente n. ${ }^{\circ} 173-$ 09-0-JR, Ministerio Público, Fiscalía de la Nación.

7 Tomás Aladino Gálvez Villegas, Autonomía del delito de lavado de activos. Cosa decidida y cosa juzgada (Lima: Ideas, 2016), 195-196.

8 Gálvez Villegas, Autonomía del delito..., 199.

9 Gálvez Villegas, Autonomía del delito..., 199-200. 
tonomía material, ya que la autonomía procesal en ningún momento estuvo en tela de juicio, razón por la cual la acreditación del delito de lavado de activos no depende de la acreditación del delito previo $^{10}$, pues, como ya se señaló, la norma penal solo hace referencia a "actividades criminales" en general y no a un delito previo concreto.

\section{TESIS DEL DELITO FUENTE COMO ELEMENTO NORMATIVO OBJETIVO DEL TIPO PENAL}

Los defensores de esta tesis sostienen que para la configuración típica del delito de lavado de activos y, por ende, para la imposición de la pena, no basta la simple afirmación abstracta y genérica de que los bienes que posee un ciudadano son ilícitos, sino que debe probar que provienen de alguno de los delitos contemplados en el segundo párrafo del artículo 10 de la ley, ${ }^{11}$ llámese minería ilegal, tráfico ilícito de drogas, terrorismo, financiamiento del terrorismo, delitos contra la administración pública, secuestro, proxenetismo, trata de personas, tráfico ilícito de armas, tráfico ilícito de migrantes, delito tributario, extorsión, robo, delitos aduaneros o cualquier otro con capacidad de generar ganancias ilegales (salvo los actos contemplados en el artículo 194 del Código Penal —receptación-).

Esto en atención al núcleo del contenido del injusto del delito de lavado de activos, es decir, dar apariencia de legalidad a bienes que provienen de la comisión de un delito previo, pues, como es de verse, siempre se exige un vínculo normativo con el "delito previo" que originó los bienes ilícitos, lo que llevaría a concluir que no existe una autonomía sustantiva del delito de lavado de activos respecto del delito que originó los bienes ilícitos; ${ }^{12}$ y es que resultaría imposible probar que los bienes tienen "origen ilícito" sin probar que provienen de un determinado delito previo. Afirmar lo contrario constituiría un petitio principii, pues se da por hecho aquello que precisamente se debería $\operatorname{probar}^{13}$.

En ese sentido, el profesor Pariona Arana nos dice que

la tesis sostiene que "únicamente se debe probar el origen ilícito y no la actividad criminal previa que produjo los bienes objeto del delito" contradice el principio de legalidad, el derecho a la prueba, el derecho de defensa y presunción de inocencia, pues resulta material-

10 Gálvez Villegas, Autonomía del delito... 202-203.

11 Raúl Pariona Arana, "La ilusión de la autonomía del delito de lavado de activos después de la dación del Decreto Legislativo $\mathrm{N}^{\circ} 1249$, ¿se puede condenar legítimamente a una persona por lavado de activos sin probar que los bienes objeto del delito provienen de la comisión de un delito previo?”, 13.

12 Raúl Pariona Arana, "La ilusión de la autonomía del delito de lavado de activos después de la dación del Decreto Legislativo $\mathrm{N}^{\circ} 1249$, ¿se puede condenar legítimamente a una persona por lavado de activos sin probar que los bienes objeto del delito provienen de la comisión de un delito previo?", 12.

13 Raúl Pariona Arana, "La ilusión de la autonomía del delito de lavado de activos después de la dación del Decreto Legislativo $\mathrm{N}^{\circ} 1249$, ¿se puede condenar legítimamente a una persona por lavado de activos sin probar que los bienes objeto del delito provienen de la comisión de un delito previo?”, 13. 
mente imposible probar el "origen ilícito" de un bien, sin determinar que proviene de un determinado delito previo, más aún, cuando la propia ley hace referencia expresa a determinadas actividades criminales contempladas en el artículo $10 .^{14}$

Por último, se agrega que "existen dos posibilidades de acreditar dicho delito previo, la primera a través de una sentencia firme anterior y la segunda en el propio proceso por delito de lavado de activos, refiriendo que en nuestro medio se ha optado por la segunda posibilidad". ${ }^{15}$

\section{NUESTRA POSTURA}

Ya habiendo explicado, groso modo, ambas posturas, es decir, la autonomía del delito de lavado de activos (sustantiva y procesal) y el delito previo como elemento normativo del tipo penal del lavado de activos y, a efectos de desarrollar mi postura personal respecto al planteamiento inicial: ¿el delito de lavado de activos tiene una autonomía sustantiva o solo procesal?, parto afirmando que si nos metemos a tal discusión, podríamos estar cometiendo una falacia, ${ }^{16}$ la falacia de falso dilema, ${ }^{17}$ pues los operadores jurídicos no necesariamente tienen que compartir una u otra postura (en sus extremos), ya que hay formas de compatibilizar ambas posturas, teniendo en cuenta la eficacia de la administración de justicia y las garantías penales, procesales y constitucionales.

En el presente artículo, desarrollaré mi posición a partir de dos principios constitucionales: el principio de legalidad y el principio de imputación necesaria.

\subsection{Análisis a partir del principio de legalidad}

De conformidad con lo dispuesto en el artículo 2, inciso 24, literal d) de nuestra Constitución Política, "Toda persona tiene derecho: (...) 24. A la libertad y a la seguridad personal. En consecuencia: (...) nadie será procesado ni condenado por un acto u omisión que al tiempo de cometerse no esté previamente calificado en la ley de manera expresa e inequívoca, como infracción punible".

El principio de legalidad no solo se configura como principio propiamente dicho, sino también como derecho subjetivo constitucional de todos los ciudadanos. Como principio

14 Raúl Pariona Arana, "La ilusión de la autonomía del delito de lavado de activos después de la dación del Decreto Legislativo $\mathrm{N}^{\circ} 1249$, ¿se puede condenar legítimamente a una persona por lavado de activos sin probar que los bienes objeto del delito provienen de la comisión de un delito previo?”, 13.

15 Dino Carlos Caro Coria y Diana Asmat Coello, "El impacto de los Acuerdos Plenarios de la Corte Suprema N. ${ }^{\circ} 03-$ 2010/CJ-116 de 16 de noviembre de 2010 y N. ${ }^{\circ}$ 7-2011/CJ-116 de 6 de diciembre de 2011 en la delimitación y persecución del delito de lavado de activos", en Imputación y sistema penal, coordinado por Abanto Vásquez, Caro John y Mayhua Quispe (Lima: ARA, 2012), 320. En: Gálvez Villegas, Autonomía del delito..., 198-199.

16 Es un razonamiento lógicamente incorrecto pero que puede ser psicológicamente persuasivo.

17 Consiste en plantear un esquema en que solo se presentan dos ideas o aspectos como las únicas opciones posibles o como excluyentes entre sí, cuando en realidad existen más opciones o hay forma de compatibilizar ambos puntos. 
constitucional informa y limita los márgenes de actuación de los que dispone el Poder Legislativo y el Poder Judicial al momento de determinar cuáles son las conductas prohibidas, así como sus respectivas sanciones; en ese sentido, garantiza a toda persona sometida a un proceso o procedimiento sancionatorio que lo prohibido se encuentre previsto en una norma previa, estricta y escrita, y también que la sanción se encuentre contemplada previamente en una norma jurídica. ${ }^{18}$

Ahora bien, el delito de lavado de activos se encuentra tipificado en el artículo 1, 2 y 3 del Decreto Legislativo 1106, de la siguiente manera:

\section{Artículo 1: Actos de conversión y transferencia}

El que convierte o transfiere dinero, bienes, efectos o ganancias cuyo origen ilícito conoce o debía presumir, con la finalidad de evitar la identificación de su origen, su incautación o decomiso, será reprimido con pena privativa de libertad no menor de ocho ni mayor de quince años.

Del tipo penal se desprenden 5 elementos que deben concurrir para la configuración de esta modalidad del delito de lavado de activos: a) la acción típica (convertir o transferir), b) el objeto del delito (dinero, bienes, efectos o ganancias, c) el origen ilícito de los activos, d) el conocimiento o deber de presunción del origen ilícito de los activos y, e) la finalidad de evitar la identificación del origen ilícito, su incautación o decomiso (elemento de tendencia interna trascendente).

\section{Artículo 2: Actos de ocultamiento y tenencia}

El que adquiere, utiliza, posee, guarda, administra, custodia, recibe, oculta o mantiene en su poder dinero, bienes efectos o ganancias, cuyo origen ilícito conoce o debía presumir, será reprimido con pena privativa de la libertad no menor de ocho ni mayor de quince años y con ciento veinte a trescientos cincuenta días multa.

Del tipo penal se desprenden 4 elementos que deben concurrir para la configuración de esta modalidad del delito de lavado de activos: a) la acción típica (adquirir, utilizar, poseer, guardar, administrar, custodiar, recibir, ocultar o mantener), b) el objeto del delito (dinero, bienes, efectos o ganancias), c) el origen ilícito de los activos y, d) el conocimiento o deber de presunción del origen ilícito de los activos.

Artículo 3: Transporte, traslado, ingreso o salida por territorio nacional de dinero o títulos valores de origen ilícito

El que transporta o traslada consigo o por cualquier medio dentro del territorio nacional dinero en efectivo o instrumentos financieros negociables emitidos "al portador" cuyo origen ilícito conoce o debía presumir, con la finalidad de evitar la identificación de su origen, su

18 Exp. No 2758-2004-HC, caso: Luis Guillermo Bedoya de Vivanco. 
incautación o decomiso; o hace ingresar o salir del país consigo o por cualquier medio tales bienes, cuyo origen ilícito conoce o debía presumir, con igual finalidad, será reprimido con pena privativa de libertad no menos de ocho ni mayor de quince años y con ciento veinte a trescientos cincuenta días multa.

Del tipo penal se desprenden 5 elementos que deben concurrir para la configuración de esta modalidad del delito de lavado de activos: a) la acción típica (trasportar o trasladar, ingresar o sacar del país), b) el objeto del delito (dinero en efectivo o instrumentos financieros negociables emitidos "al portador", c) el origen ilícito de los activos, d) el conocimiento o deber de presunción del origen ilícitos de los activos y, e) la finalidad de evitar la identificación de su origen, su incautación o decomiso (elemento de tendencia interna trascendente).

Como es de verse, el origen ilícito de los activos es un elemento normativo del tipo penal, razón por la cual se requiere de su probanza.

Pero, ¿qué significa origen ilícito? "Origen”, según la RAE, es el principio, nacimiento, raíz y causa de algo; por otro lado, la "ilicitud” es la que prevé la norma como antecedente de una sanción, ${ }^{19}$ es decir, la norma describe una conducta a la que corresponde una sanción: esa conducta, prevista como antecedente de una sanción, es lo ilícito; asimismo, la ilicitud solo puede resultar de una norma jurídico-positiva, ${ }^{20}$ pues un hecho que no ha sido consagrado normativamente como presupuesto de una sanción no es ilícito.

Entonces, debemos entender el origen ilícito de los activos como la raíz, el nacimiento de los activos provenientes de infracciones normativas. Ahora bien, de la lectura y análisis de los tipos penales consagrados en los artículos 1, 2 y 3 del Decreto Legislativo 1106, y a efectos de no caer en el error de considerar que los activos puedan provenir de ilícitos no necesariamente penales, es necesario realizar una interpretación sistemática a la norma penal de lavado de activos en relación al origen ilícito (Decreto Legislativo 1106), que establece en su artículo 10 lo siguiente:

\section{Artículo 10. Autonomía del delito y prueba indiciaria}

El lavado de activos es un delito autónomo por lo que para su investigación, procesamiento y sanción no es necesario que las actividades criminales que produjeron el dinero, los bienes, efectos o ganancias, hayan sido descubiertas, se encuentren sometidas a investigación, proceso judicial o hayan sido previamente objeto de prueba o condena

El conocimiento del origen ilícito que tiene o que debía presumir el agente de los delitos que contempla el presente Decreto Legislativo, corresponde a actividades criminales como los delitos de minería ilegal, el tráfico ilícito de drogas, el terrorismo, el financiamiento del

19 Enciclopedia Jurídica Omeba, tomo XIV (Argentina: Briskill S. A., 1982), 965.

20 Enciclopedia Jurídica Omeba, tomo XIV (Argentina: Briskill S. A., 1982), 967. 
terrorismo, los delitos contra la administración pública, el secuestro, el proxenetismo, la trata de personas, el tráfico ilícito de armas, tráfico ilícito de migrantes, los delitos tributarios, la extorsión, el robo, los delitos aduaneros o cualquier otro con capacidad de generar ganancias ilegales, con excepción de los actos contemplados en el artículo $194^{\circ}$ del Código Penal. El origen ilícito que conoce o debía presumir el agente del delito podrá inferirse de los indicios concurrentes en cada caso.

Tal y como señala el artículo 10 del Decreto Legislativo 1106, el origen ilícito corresponde a actividades criminales. Pero, ¿qué debemos entender por actividades criminales? Pareciera que el profesor Gálvez Villegas pretende hacer una diferencia entre la terminología "actividad criminal" y "delito previo", pues señala que "la norma peruana no hace referencia a delito previo sino a actividad criminal, lo que significa una consideración general y abstracta de la actividad delictiva a la cual deben estar vinculados los activos". ${ }^{21}$

En realidad, la actividad criminal no es otra cosa que la actividad consistente en cometer ilícitos graves, los mismos que tienen que ser, cuanto menos, típicos y antijurídicos. $Y$ es que, el "delito grave" y la "actividad criminal" se identifican con el concepto y la acción, respectivamente, de una misma realidad de todo indisoluble. ${ }^{22}$

En este aspecto, el profesor García Cavero no se hace mayor problema, pues relaciona directamente la terminología "actividades criminales" con el "delito previo"; así, señala: "De necesaria dilucidación es el término 'actividades criminales' con el que se califica al delito previo en el delito de lavado de activos". 23

Ahora bien, debe quedar claro que la actividad criminal previa o delito previo debe entenderse en un sentido limitado, es decir, solo es necesario que la conducta previa que genera los activos maculados sea típica y antijurídica, ${ }^{24}$ pues la ilegitimidad de la adquisición de las ganancias se sustenta únicamente en la antijuricidad de la conducta que las genera. ${ }^{25}$ En ese sentido, si al autor del delito previo no se le sanciona por la exclusión de la culpabilidad o pu-

21 Gálvez Villegas, Autonomía del delito..., 212.

22 En España, Jerónimo García San Martín hace la misma diferenciación, pero en cuanto a "delito" y actividad delictiva”. En Jerónimo García San Martín, "La concreción del delito antecedente en el blanqueo de capitales", Diario La Ley, n. ${ }^{\circ}$ 8587 (2015): 3.

23 Percy García Cavero, Derecho penal económico. Parte especial, volumen I (Lima: Pacífico Editores, 2015), 579.

24 Vid., así, Castilllo Alva, Gaceta Penal \& Procesal Penal 4 (octubre de 2009): 341; Pérez López, Gaceta Penal \& Procesal Penal 35 (mayo 2012): 62; Jiménez Bernales, Gaceta Penal \& Procesal Penal 17 (noviembre 2010): 33. Igualmente, en otras regulaciones penales Kindhauser, LPK-StGB, 261, n.m.3; Altenhain, NomosKommentar StGB, 261, n.m.31; Isidoro Blanco Cordero, El delito de blanqueo de capitales (Pamplona: Aranzadi, 2012), 263; Carlos Aránguez Sánchez, El delito de blanqueo de capitales (España: Marcial Pons, 2000), 198 y ss.; Eduardo A. Fabián Caparrós, El delito de blanqueo de capitales (Madrid: Colex, 1998), 291; Del Carpio Delgado, en José Urquizo Olaechea y Nelson Salazar Sánchez, coords., Política criminal (Lima: Universidad de San Martín de Porres, 2011), 76; Carlos Martínez-Bujan Pérez, Derecho penal económico (Madrid: Iustel Publicaciones, 2012), 503. En Percy García Cavero, Derecho penal económico..., 580.

25 Idem. 
nibilidad, entonces sí es posible que quien proceda a lavar los activos provenientes del injusto responda penalmente por el delito de lavado de activos.

En conclusión, queda claro que el delito previo, en sentido estricto, no es un elemento normativo del tipo penal de lavado de activos; el elemento normativo del tipo penal de lavado de activos es el origen ilícito, que no es otra cosa que - de acuerdo a una interpretación sistemática de la norma penal - la procedencia criminal del activo. Así, el profesor García Cavero señala que "el tipo penal de lavado de activos no sanciona un acto generador de activos y el posterior proceso de lavado de esos activos. Lo único que castiga es el acto de lavado. Por lo tanto, el elemento típico no es, en estricto, el delito previo, sino la procedencia delictiva de los activos lavados".

\subsection{Análisis a partir del principio de imputación necesaria}

La imputación necesaria es una manifestación del principio de legalidad y del principio de la defensa procesal (artículo 2.24 "d" y 139.14 de la Constitución Política del Perú); ${ }^{26}$ en virtud de este principio se exige una atribución clara, precisa, explícita, detallada y circunstanciada de una comunicación con apariencia delictiva concretamente individualizada, a una persona determinada, con un nivel de vinculación ciertamente probable; a efectos de que esta tenga la posibilidad de ejercitar eficazmente su derecho de defensa.

Ahora bien, tal y como afirma la profesora Herrera Guerrero, “el Decreto Legislativo 1106 que regula el delito de lavado de activos en nuestro país, si bien tiene una clara finalidad represiva, debe ser interpretado teniendo en cuenta garantías penales y procesales mínimas, una de ellas — de gran relevancia en todo el proceso penal en un Estado de derecho- es precisamente el principio de imputación necesaria”. ${ }^{27}$

Conforme hemos señalado en el punto anterior, uno de los elementos normativos del tipo penal de lavado de activos es el origen ilícito —entendido como la procedencia criminal del activo-, y no así el delito fuente, en sentido estricto. Entonces, el Decreto Legislativo 1106 no exige la probanza del delito previo, pero sí la determinación de los aspectos esenciales de la procedencia criminal de los activos - elemento normativo del tipo penal- . Es así que, conforme lo señala la profesora Herrera Guerrero, es necesario contar una atribución específica, circunstanciada en tiempo y espacio, para así poder ejercer adecuadamente el derecho de defensa. ${ }^{28}$ Entonces, debe quedar claro que los activos no proceden de actividades ilícitas indefinidas, sino solamente de la comisión de delitos concretos, por lo que deberá acreditarse

26 Recurso de Nulidad n. ${ }^{\circ}$ 956-2011-Ucayali.

27 Mercedes Herrera Guerrero, "La prueba de la procedencia delictiva de los bienes en el delito de lavado de activos, una primera aproximación", Actualidad Penal, n. ${ }^{\circ} 24$ (2016): 217.

28 Mercedes Herrera Guerrero, "La prueba de la procedencia delictiva de los bienes en el delito de lavado de activos, una primera aproximación”, 219 
que el activo materia de lavado proviene de un hecho delictivo determinado. ${ }^{29}$

Si bien es cierto que el artículo 10 del Decreto Legislativo 1106, modificado por el Decreto Legislativo 1249, señala que "el lavado de activos es un delito autónomo por lo que para su investigación, procesamiento y sanción no es necesario que las actividades criminales que produjeron el dinero, los bienes, efectos o ganancias, hayan sido descubiertas, se encuentren sometidas a investigación, proceso judicial o hayan sido previamente objeto de prueba o condena”, es imposible, jurídicamente hablando, que se pueda determinar la procedencia criminal de un activo, si no se demuestra, por lo menos, el carácter delictivo en sus aspectos sustanciales (tipicidad y antijuricidad).

En ese sentido y, a efectos de poder dar al citado texto normativo un sentido acorde al principio de imputación necesaria, considero que su interpretación podría darse de la siguiente manera:

- El delito de lavado de activos es un delito autónomo, por lo que para su investigación (...) no es necesario que las actividades criminales que produjeron el dinero, los bienes, efectos o ganancias, hayan sido descubiertas (...).

- El delito de lavado de activos es un delito autónomo, por lo que para su (...) procesamiento y sanción no es necesario que las actividades criminales que produjeron el dinero, los bienes, efectos o ganancias, (...) se encuentren sometidas a investigación, proceso judicial o hayan sido previamente objeto de prueba o condena.

Entonces, podría decirse que al inicio de las diligencias preliminares no se requiere que la actividad criminal previa haya sido descubierta, pues en efecto, en fase preliminar solo existe una sospecha simple del supuesto acto de lavado. Ahora bien, la figura cambia cuando se formaliza investigación preparatoria, pues si bien no es necesario que la actividad criminal previa se encuentre sometida a investigación, proceso judicial o haya sido previamente objeto de prueba o condena (pues, como se señaló, no importa la culpabilidad ni punibilidad de la actividad criminal previa, solo la tipicidad y antijuricidad), sí se requiere que el Ministerio Público indique la probable actividad criminal que produjo las ganancias ilícitas, circunstanciada en tiempo y espacio, garantizando así el derecho de defensa (principio constitucional).

Veamos un ejemplo. En Juliaca, intervienen a Juan Pérez, ciudadano con estudios secundarios incompletos, comprando un inmueble valorizado en S/ 300 000,00 nuevos soles. Al no poder este justificar documentariamente el origen de su dinero, el fiscal apertura diligencias preliminares; para entonces, en efecto, no es necesario que la supuesta actividad criminal previa haya sido descubierta, pues tiene el plazo determinado por ley para poder realizar

29 Percy García Cavero, Derecho penal económico..., 579. 
las diligencias correspondientes a efectos de recabar los medios probatorios suficientes que permitan fundamentar su decisión (formalización de investigación preparatoria o archivo de la investigación). Ahora bien, en el transcurso de las diligencias preliminares, el fiscal podrá recabar la mayor información posible a través de diversas diligencias. En ese sentido, el fiscal podría advertir que Juan Pérez, a partir del 2012, viaja constantemente a la mina Rinconada, donde radican sus hermanos y su esposa tiene su negocio de compra y venta de oro. Como es de verse, ya para la formalización de investigación preparatoria la figura cambia, pues el fiscal podrá indicar la probable actividad criminal que produjo las supuestas ganancias ilícitas, es decir, minería ilegal.

Por lo expuesto, queda claro que se tiene que probar la procedencia criminal de los activos (elemento normativo del tipo penal), su acreditación, tal y como lo ha señalado la Sala Penal Transitoria mediante Recurso de Nulidad No 2868-2014-LIMA, y debe confirmarse -indistintamente con prueba directa y/o prueba indiciaria, ambas en plano de igualdad; aunque la última, que no es por ello más insegura ni subsidiaria, es la más común en estos casos- en la causa incoada por delito de lavado de activos. Debe probarse algún vínculo o conexión con actividades delictivas graves o con personas o grupos relacionados con ese delito. ${ }^{30}$

Si bien es cierto que no hace falta la investigación o sentencia de la actividad criminal previa que haya generado las ganancias ilícitas, ello no significa que quede al margen de la actividad probatoria, pues como bien lo señala el Recurso de Nulidad № 2868-2014-Lima, se tiene que probar i) que tal situación se acredite en sus aspectos sustanciales, que permitan delinear el carácter delictivo de la misma, y ii) que la prueba de tal situación delictiva del activo maculado en cuestión debe equipararse a los estándares racionales de la acreditación delictiva en general.

En conclusión, lo que realmente se exige en el delito de lavado de activos es la acreditación necesaria de que los bienes, inicialmente bajo sospecha simple, y luego bajo sospecha suficiente, tuvieron su origen en una actividad criminal previa, ${ }^{31}$ la misma que debe especificarse y delimitar en determinada fecha y en determinadas circunstancias, pues como se ha señalado, no queda al margen de la actividad probatoria; y es que existe una dependencia entre la actividad criminal previa y el acto propio de lavado, esto, en virtud de que la sanción del lavado de activos depende de la realización típica y antijurídica de un delito previo.

30 Recurso de Nulidad 2868-2014-LIMA, Sala Penal Transitoria de la Corte Suprema de la República.

31 Recurso de Nulidad 2868-2014-LIMA, Sala Penal Transitoria de la Corte Suprema de la República. 


\section{CONCLUSIONES}

La discusión de la autonomía del delito de lavado de activos, respecto al delito fuente, se ha convertido en un tema de permanente discusión en la doctrina peruana; considero que no es necesario tomar posturas extremas, pues solo generan confusión en el operador jurídico. ¿El delito de lavado de activos es autónomo? Si. ¿Se requiere la investigación o sanción del delito precedente? No. ¿Es autónomo respecto a otros delitos (receptación, encubrimiento)? Sí. ¿El delito previo es un elemento normativo del tipo penal? No. ¿El delito previo queda al margen de la actividad probatoria? No.

\section{REFERENCIAS}

- Aránguez Sánchez, Carlos. El delito de blanqueo de capitales. España: Marcial Pons, 2000.

- Blanco Cordero, Isidoro. El delito de blanqueo de capitales. Pamplona: Aranzadi, 2012.

- Caro Coria, Dino Carlos y Diana Asmat Coello. "El impacto de los Acuerdos Plenarios de la Corte Suprema No 03-2010/CJ-116 de 16 de noviembre de 2010 y No 7-2011/ CJ-116 de 6 de diciembre de 2011 en la delimitación y persecución del delito de lavado de activos". En Imputación y sistema penal, coordinado por Abanto Vásquez, Caro John y Mayhua Quispe. Lima: ARA, 2012.

- Castillo Alva, José Luis. "La necesidad de determinación del delito previo en el delito de lavado de activos. Una propuesta de interpretación constitucional”. Gaceta Penal, n. ${ }^{\circ} 4$ (2009).

- Enciclopedia Jurídica Omeba. Tomo XIV. Argentina: Briskill S. A., 1982.

- Fabián Caparrós, Eduardo A. El delito de blanqueo de capitales. Madrid: Colex, 1998.

- Gálvez Villegas, Tomás Aladino. Autonomía del delito de lavado de activos. Cosa decidida y cosa juzgada. Lima: Ideas, 2016.

- García Cavero, Percy. Derecho penal económico. Parte especial. Volumen I. Lima: Pacífico Editores, 2015.

- García San Martín, Jerónimo. "La concreción del delito antecedente en el blanqueo de capitales". Diario La Ley, n. 8587 (2015).

- Herrera Guerrero, Mercedes. "La prueba de la procedencia delictiva de los bienes en el delito de lavado de activos, una primera aproximación”. Actualidad Penal, n. 24 (2016).

- Hinostroza Pariachi, César. El delito de lavado de activos. Delito fuente. Lima: Grijley, 2010. 
- Martínez-Bujan Pérez, Carlos. Derecho penal económico. Madrid: Iustel Publicaciones, 2012.

- Pariona Arana, Raúl. "La ilusión de la autonomía del delito de lavado de activos después de la dación del Decreto Legislativo $\mathrm{N}^{\circ} 1249$, ¿se puede condenar legítimamente a una persona por lavado de activos sin probar que los bienes objeto del delito provienen de la comisión de un delito previo? Gaceta Penal, n. ${ }^{\circ} 90$ (2016).

- Prado Saldarriaga, Víctor Roberto. "Jurisprudencia reciente de la Corte Suprema relacionada con el delito de lavado de activos". Acceso el 28 de mayo de 2017. http://www. mpfn.gob.pe/escuela/contenido/actividades/docs/3247_lav_activos_2.pdf.

- Urquizo Olaechea, José y Nelson Salazar Sánchez, coords., Política criminal. Lima: Universidad de San Martín de Porres, 2011. 